\title{
APROXIMACIÓN A LOS CRITERIOS PRECAUTORIOS DESDE LA POLÍTICA AMBIENTAL Y SUS RELACIONES CON LA CIENCIA Y LA SOCIEDAD
}

\author{
overview on the precaution from the environmental policy \\ and their relations with the science and the society
}

Maria Àngels Alió i Torres*

\begin{abstract}
Resumo
Este artigo oferece uma aproximação analítica ao critério da precaução, tradicionalmente valorizado e orientado às políticas ambientais e de saúde, especialmente no que concerneaos estudos das ciências sociais e da geografia. O trabalho consiste em cinco partes. A primeira centra-se na definição do conceito, intimamente ligado ao desenvolvimento de alternativas, face ao processo de degradação ambiental da sociedade contemporânea. A segunda parte apresenta a cronologia de sua introdução no sistema jurídico contemporâneo, com especial ênfase em alguns momentos que foram importantes no seu desenvolvimento jurídico. A terceira parte analisa o papel da ciência no contexto contemporâneo, especialmente no tocante à construção das estruturas legislativas e da política ambiental de precaução, as quais estão intimamente ligadas às ideias de riscos e perigos ambientais,que requer das ciências e do mundo acadêmico especial atenção analítica e investigativa. A quarta parte trata a questão da base social de precaução, trazendo uma série de estudos de casos e experiências que podem servir como exemplos de como o desenvolvimento normativo e científico da precaucãotambém está intimamente ligadoàs demandas da sociedade. $\mathrm{O}$ artigo termina com uma breve conclusão propositiva, apresentando algumas ideias de como o problema e a abordagem em questão pode ser de interesse da geografia.
\end{abstract}

Palavras-chave: Precaução, Prevenção, Riscos socioambientais, Sustentabilidade, Ciência, Movimentos Sociais.

\begin{abstract}
The paper offers an approximation to precaution criteria, from long time oriented to environmental policy and the health, and with special affectation to social sciences. This work has five parts. The first is centered in the definition of the concept, developed next to emergency alternative proposals to degradation of environment in our contemporary society. The second part presents an overview of their introduction into the legislation system, with attention in any moments that were importants during their legal developing process. Following, the third part treats on the science role in the contemporary process of the construction of the legal environmental policy structures, a lot linked to the risk and hazard framework, and the responses that are demanded to scientists and to the research. The fourth place presents cases and experiences that can serve of example as the laws and scientific results on the precaution are linked to demand of society. Finally, the paper is closing with a brief conclusion with some ideas on the precaution issue can be of a lot interest also for the geography.
\end{abstract}

Key words: Precaution, Prevention, Socio-environmental hazards, Sustainability, Science, Social Movements

\begin{abstract}
Resumen
Este artículo ofrece una aproximación al criterio de la precaución, tradicionalmente orientado a las políticas ambientales y de la salud y con especial trascendencia en las ciencias sociales y la geografía. El trabajo consta de cinco partes. La primera se centra en la definición del concepto, íntimamente unido al desarrollo de alternativas al proceso de degradación ambiental de la sociedad contemporánea. La segunda presenta la cronología de su introducción en el sistema legislativo contemporáneo, poniendo especial énfasis en algunos momentos que fueron importantes en su desarrollo jurídico. La tercera parte plantea el papel de la ciencia en el marco del proceso contemporáneo de construcción de las estructuras legislativas y de la política ambiental precautoria y que están estrechamente unidas a los planteamientos sobre el riesgo y los peligros ambientales y a las respuestas que se le piden al mundo académico y a la investigación. La cuarta parte trata el tema de la base social de la precaución y desarrolla una serie de casos y experiencias que pueden servir de ejemplo sobre como el desarrollo normativo y científico de la precaución también está estrechamente unido a la demanda de la sociedad. El artículo se cierra con una conclusión que, de manera muy resumida, propone algunas ideas sobre cómo el tema precautorio puede ser de interés en la geografía.
\end{abstract}

Palabras-Claves: Precaución, Prevención en origen, Peligros socioambientales, Sostenibilidad, Ciencia, Movimientos sociales.

(*) Prof ${ }^{a}$. Dra . da Universitat de Barcelona - Gran Via de les Corts Catalanes, CEP: 585 08007, Barcelona, Espanha, Tel/Fax: (+34 93)3333466/3330614 - alio@ub.edu 


\section{INTRODUCCIÓN}

En este artículo se ofrece una aproximación al criterio de la precaución, tradicionalmente orientado a las políticas ambientales y de la salud, pero que también tiene especial trascendencia en las ciencias sociales y la geografía. Con este objetivo vamos a presentar un recorrido desde mediados del siglo pasado, cuando la precaución hizo irrupción como estrategia preventiva hasta pasar a formar parte, en nuestros días, de las nuevas líneas de intervención política y legal. Veremos, sin embargo, que a la precaución le queda un largo camino por recorrer.

Con este objetivo hemos dividido nuestro texto en cinco partes. La primera se centra en la definición del concepto, íntimamente unido al desarrollo de alternativas al proceso de degradación ambiental de la sociedad contemporánea. La segunda tiene por objeto presentar una secuencia de su introducción en el sistema legislativo contemporáneo, poniendo especial énfasis en algunos momentos que fueron importantes en su desarrollo jurídico. A continuación, en la tercera parte, se plantea el papel de la ciencia en el marco de este mismo proceso actual de construcción de las estructuras legislativas y de la nueva política ambiental, estrechamente unidas a los planteamientos sobre el riesgo y los peligros y a las respuestas que se le piden al mundo académico y a la investigación. A continuación, la cuarta parte presenta una serie de experiencias protagonizadas por diversos colectivos sociales que son capaces de materializar el criterio precautorio en el día a día de sus prácticas y actividades. Y que en resumen, vendrían a demostrar que también en este caso el desarrollo normativo y científico se haya estrechamente asociado a las presiones y demandas de la sociedad. Finalmente, el artículo se cierra con una conclusión que, de manera muy resumida, propone algunas ideas sobre cómo el tema precautorio puede ser de interés en la geografía.

\section{LA DEFINICIÓN DEL CRITERIO PRECAUTORIO Y SUS CONCEPTOS}

Desde siempre, se ha entendido que la precaución es una medida destinada a evitar un mal, y como una actitud de prudencia frente a la posibilidad de un determinado peligro. Así, el concepto de precaución enlaza con las actitudes psicosociales y el instinto que las personas tenemos en nuestro interior. Pero las cosas son muy distintas, por no decir contradictorias, cuando se trata de aplicarla a la sociedad moderna, tan imbuida de la seguridad de sus instrumentos de protección y control.

Por consiguiente, convendría empezar este apartado explicando que la idea contemporánea de precaución nace a finales de los cincuenta en el siglo pasado en el marco de las movilizaciones ciudadanas y ecologistas contra la nuclearización y las substancias industriales tóxicas que se empezaban a usar entonces masivamente para el control de las plagas agrícolas, y para las cuales se reivindicaba acciones legales de prohibición. Estas movilizaciones fueron el inicio de un fenómeno complementario al desarrollo científico y cultural de una nueva mentalidad sobre las relaciones entre la sociedad y la naturaleza, y en el que también tuvieron su papel un pequeño círculo de científicos a quienes debemos, de hecho, las primeras formulaciones sistemáticas y razonadas del concepto precautorio.

\section{El desarrollo contemporáneo del concepto}

El primer libro enteramente dedicado a la precaución apareció en1994 en forma de recopilación de textos editada por el geógrafo O'Riordan y el abogado Cameron (1994). Poco después, una nueva corriente de científicos, entre ellos el mismo O'Riordan, profundizaron en el tema reforzando este nuevo gran tema de análisis y reflexión. El mismo O’Riordan, junto a Jordan, otro geógrafo, conformaron una línea de investigación y estudio a caballo entre la política, la geografía y las ciencias sociales (1995 y 1998). Con estos trabajos hicieron emerger una serie de ideas. La primera, que el concepto precautorio enlaza el instinto humano del cuidado y la protección con la necesidad de un desarrollo legislativo específico tanto para la salud como para el medio ambiente. La segunda, que uno de los potenciales más interesantes de la precaución consiste en que puede ser 
un instrumento complementario al de sostenibilidad. Básicamente, porqué, proporciona una guía sencilla, comprensible para todo el mundo, que puede aplicarse en situaciones complejas con daños para las personas y el medioambiente. Y la tercera, porque el criterio precautorio tiene capacidad para transformarse en instrumento de carácter legal para regular las decisiones que deben tomarse para evitar males, incluso en situaciones en que no se pueda contar con certidumbres absolutas respecto a los orígenes del mal.

El siguiente paso en el proceso de conformación contemporánea del concepto se produjo en 1988 en el Congreso Internacional de Wingspread, que reunió personalidades científicas de múltiples disciplinas, entre ellas la misma geografía. Hay dos circunstancias que justifican la relevancia de este congreso. Una, este mismo carácter transdisciplinar, aunque el comité organizador estuviera constituido inicialmente por expertos vinculados a la salud pública, una de las áreas que ya venía interesándose por la precaución desde hacia tiempo. Y dos, que concluyera con una declaración que ratificaba la idea que las medidas precautorias debían tomarse siempre que hubiese posibilidad de un daño para la salud o el medio ambiente, incluso aun cuando algunas relaciones de causa - efecto no pudieran haberse demostrado científicamente.

Aunque más adelante vamos a volver sobre los significados de este congreso queremos insistir ahora en su contribución decisiva en el proceso de desarrollo científico del concepto de la precaución, que incluía también la idea del no hacer. Con las consiguientes dificultades a la hora de aplicarlas en un marco legal y de gestión dominado por los planteamientos positivistas de las relaciones causales. Y que por otra parte, enlazaba con las incertidumbres e interrogantes de este mismo no hacer, un tema clave para la ciencia y al que volveremos más adelante. Otro factor no menos importante radicaba, probablemente, en que todo ello abría las puertas a la complejidad de factores y relaciones implicadas en las problemáticas socio-ambientales, en un contexto de especialización científica y de un desarrollo legal y de gestión extremadamente compartimentado.

Para terminar esta aproximación a la precaución cabe añadir que recientemente ha empezado a ganar acepción la idea de la precaución de segunda generación, formulada por primera vez por William R. Jordan (1994) para designar acciones precautorias en situaciones de extrema complejidad, asociadas a males que fueron producidos en el pasado y que enlazan, por tanto, con fenómenos actuales de contaminación. Los cuales pueden relacionarse, además, con procesos interescalares, incluida la dispersión de la contaminación en la escala global.

\section{Un concepto complejo con significados distintos}

En un esfuerzo por clarificar una situación en la que se confunden las ideas sobre lo que es o no es precaución hay que distinguir entre las prohibiciones referidas a circunstancias de las cuales se conoce suficientemente el agente causal del mal, para las que se ha derivado la definición de prevención en origen, y las restricciones que conciernen a actividades de las que se tiene serias dudas sobre su inocuidad, pero sobre las que no existe certeza sobre su responsabilidad causal en los impactos. En el primer caso, nos hallamos ante una estrategia precautoria que se resume en la idea clásica del no hacer, y que se remonta a mediados del siglo pasado, aunque en realidad no se haya aplicado con la rapidez e intensidad deseables. En el segundo, se trata de medidas para situaciones heterogéneas, poco determinadas a veces en relación con sus causas, pero respecto a las cuales se hace imprescindible intervenir con acciones que interactúan y se retroalimentan entre sí. Por lo general van asociados a riesgos de diferente índole, incluso peligros que pueden derivar en verdaderas catástrofes.

A estas dos definiciones habría que añadir la precaución de segunda generación, que pone el acento en las intervenciones para resolver los problemas generados en el pasado, y que se sumarian a las que se realizan en el presente.

En un intento por acercar la ciencia a la política legislativa Tickner (2003), uno de los organizadores del congreso de Wingspread, propuso una esquematización muy simple de los distintos 
aspectos legislativos implicados en la aplicación del criterio precautorio. El primer lugar lo reservaba a las figuras legales propiamente dichas, concretamente la prohibición o la supresión de algo respecto del que se tiene la certeza que está implicado en la generación de los males que se espera evitar y para el que se reserva el concepto de prevención en origen.

Este primer nivel legislativo se acompaña de un segundo nivel, formado por un conjunto heterogéneo de acciones complementarias y de refuerzo de la prohibición, pero que también deben ser de consideración obligatoria tanto en el sector público como privado. Estas acciones complementarias son las siguientes: a) la fijación de metas y medidas bien definidas para periodos de tiempo determinado, y que están destinadas a reforzar y concretar la aplicación concreta de la prohibición; b) el traspaso de la responsabilidad de la evidencia de la supuesta inocuidad a los agentes implicados en el posible daño o impacto, acción ésta de gran trascendencia en un entorno legislativo que permite la circulación en los mercados de nuevos productos industriales de los que no existe certeza de su inocuidad; c) el desarrollo de métodos más democráticos y exhaustivos para la toma de decisiones; Y finalmente d) medidas económicas -desde las tasas a los incentivos, pasando por la fijación de precios- que obliguen a las empresas a considerar los costes de la no precaución así como a internalizar las plusvalías ambientales resultantes de los impactos.

\section{EL DESARROLLO LEGISLATIVO DE LA PRECAUCIÓN EN EL ÁMBITO ESTATAL E INTERNACIONAL}

Hasta aquí una breve introducción a los significados de la precaución. Vamos a adentrarnos ahora en su desarrollo legislativo desde sus inicios, en una larga primera fase asociada fundamentalmente a la prevención en origen, hasta la actualidad.

El inicio de esta cronología tiene sus antecedentes en 1953, cuando el joven biólogo Commoner reclamaba el fin de las pruebas nucleares alegando que era imposible establecer ningún umbral de seguridad para la salud humana y el medio ambiente en el campo de la contaminación radioactiva. Pocos después, en 1962, Carson utilizaba la misma argumentación cuando abogaba por la prohibición de fabricación y uso de determinadas sustancias tóxicas, fundamentalmente organoclorados, a causa de su responsabilidad en la salud de las personas y el medio ambiente en general. Ya veremos que, con excepciones, esta fuerte asociación entre la precaución por un lado y la salud y el medio ambiente por el otro, ha presidido gran parte de la evolución legislativa.

De hecho, la legislación no arranca hasta casi veinte años después, cuando Estados Unidos prohibió el uso del DDT en 1972 y Suecia lo hacía en 1975. En el intermedio, la Cumbre de Estocolmo podía haber sido la primera ocasión que hubiera permitido adoptarla en el marco internacional, pero no fue hasta los años ochenta que Suecia y la antigua Alemania Occidental acordaron establecer conjuntamente el criterio precautorio para frenar la contaminación de las aguas del Mar Báltico. Paralelamente, y a causa de sus consecuencias en la salud pública, algunos estados habían empezado a obligar a la disminución de las dosis permitidas de determinados metales pesados en el aire, el agua y la alimentación. (KRIEBEL; ALTER, 2001, p. 871-872, O'RIORDAN; JORDAN, 1995, p.191-192).

Con todo, ya hemos dicho que no es hasta 1992, con la Cumbre de las Naciones Unidas de Río de Janeiro, que empieza formalmente el proceso de consolidación de la precaución como instrumento legal internacional. Éste se inició en 1991 de la mano del panel sobre el cambio climático que fue quien introdujo la hipótesis de la precaución como estrategia futura para la reducción de los impactos de la actividad económica en el calentamiento global. La cual se aprobaría finalmente en la Cumbre de Río como uno de los instrumentos principales en el proceso de implantación del principio de la sostenibilidad. Fue entonces cuando la precaución -y la participación ciudadana, otro de los criterios que emergieron entonces como instrumento de la política ambiental- se constituyó en uno de los núcleos básicos de la investigación científica, tal como ya se ha apuntado antes al 
comentar los trabajos de O’Riordan y Jordan y la celebración del Congreso Wingspread.

En realidad, el desarrollo precautorio inmediatamente posterior siguió un camino muy dispar, dependiendo más de la dialéctica política y la correlación de fuerzas entre los actores implicados que no de los acuerdos formales de las Naciones Unidas. Un hito importante fue su incorporación en la lista de criterios de gestión de las Agendas 21 Local europeas en 1994 (Hewitt, 1996). Otro hecho importante fue la formalización del criterio de la prevención en origen para las sustancias tóxicas en el estado norteamericano de Massachussets (TICKNER; RAFFENSPERGER; MYERS, 2001, p.2). Desde entonces hasta ahora, múltiples administraciones locales y regionales de todo el mundo han ido añadiéndose a este proceso de dotarse de normas propias, especialmente para la prevención en origen y para los sectores más vulnerables de población. Este proceso ha continuado hasta nuestros días, aunque en realidad solo ha llegado a ser incorporado en los municipios ambientalmente más sensibles.

Otros hechos positivos para el mismo periodo fueron la aprobación en 1994 del principio de la prevención en origen para la generación de dioxinas en los procesos de incineración por parte de la Environmental Protection Agency - EPA de los Estados Unidos. Y también la aprobación en 1999 en Canadá de la ley para la protección del medio ambiente, ampliada en 2003 con la obligación de aplicar el principio de la precaución a 23.000 substancias que se comercializaban entonces en el conjunto de este estado (TRUDEAU; BEAULNE-BÉLISEY; LEROUX, 2010).

También desde finales del siglo pasado la Unión Europea había empezado a adentrarse en la política precautoria, siendo de destacar la directiva sobre la composición de la alimentación para rumiantes que culminó en la prohibición taxativa de toda una serie de líneas alimentarias para la carne de vacuno en el marco de la directiva conocida como de las vacas locas de 1999. Al tiempo que también se hacían los primeros intentos precautorios en el ámbito mundial de la contaminación y el cambio climático. Concretados en la propuesta europea de 1997 de reducción en origen del $20 \%$ de las emisiones de gases de efecto invernadero en la Cumbre de Kioto. Aunque ya es conocido que ésta no llegó a aprobarse, pudiendo considerarse por ello que la Cumbre de Kioto fue el punto álgido de un buen acuerdo internacional que no llegó a materializarse después que buena parte de los estados no ratificasen los acuerdos de aquella cumbre. De donde podríamos afirmar que continuaba la situación de enroque que hemos comentado más arriba.

Esta misma realidad se reproduce en otros ámbitos. Por ejemplo, y para el caso d de los fertilizantes químicos, se constata un avance legal desde el momento que el Convenio de Estocolmo del 2001, ratificado por 150 estados, se dispone desde 2004 de un Reglamento que sanciona la prevención en origen prohibiendo la producción y el uso de 12 compuestos orgánicos persistentes (PORTA; ALTER, 2002 y 2006). Poco después, en 2006, el Convenio de Rotterdam profundizaba en la misma dirección estableciendo medidas restrictivas para las sustancias tóxicas y peligrosas y también para el comercio internacional de plaguicidas en un intento para aplicar las restricciones en el marco internacional de la estructura económica desigual. Aunque, por parte, en algunos estados continúe el uso intensivo de estos productos. Concretamente, en Brasil, persiste la aplicación y fabricación de agrotóxicos al amparo de enmiendas que tornan inoperantes las leyes generales y flexibilizan su uso en la práctica (AUGUSTO, 2011). Con los consiguientes problemas de salud entre los trabajadores agrícolas y la difusión de contaminantes a través de la alimentación y la contaminación del suelo y del agua. (RIGOTTO, 2011 a).

Por otra parte, también persiste en el medio la contaminación que se ha ido acumulando en los seres vivos de los ecosistemas, tanto en la fauna como en la flora y el suelo. Quizás Canadá sea uno de los estados donde se ha hecho más patente esta situación. En parte porque es uno de los que ha avanzado más en el ejercicio de la normativa precautoria y en parte, también, por su ubicación en el marco del régimen general de la circulación atmosférica, que propicia la deposición de las partículas que se han ido emitidas en las últimas décadas, las cuales se han ido bioacomulando en las cadenas tróficas, con especial incidencia en los grandes mamíferos árticos. 
De este modo, puede observarse que incluso en países donde existen datos positivos, esta realidad contradictoria sea probablemente la característica más relevante del desarrollo legislativo precautorio de nuestros días. Veamos todavía otros dos ejemplos europeos. El primero, la Directiva Europea de 2004 sobre gestión de residuos, todavía vigente, que no sanciona la incineración de residuos en base a la argumentación que contribuye a la generación de energía. Aún cuando la misma directiva contiene normas específicas que favorecen el compostaje de la fracción orgánica de los residuos municipales. Y el segundo, también para la Unión Europea, el reglamento de 2006, ampliado en 2010 y 2011, que se conoce con el nombre REACH y que contempla la restricción de una serie de sustancias tóxicas así como la obligatoriedad de todos los agentes económicos implicados, incluidos los fabricantes, de garantizar y demostrar la inocuidad de las substancias que fabrican, comercializan o manipulan.

Ya para terminar este apartado convendría añadir algunas referencias sobre el cultivo y manipulación de substancias transgénicas. Otro de los grandes temas que se ha añadido recientemente a la lista de temas necesitados de ser tratados desde la perspectiva precautoria. Más todavía si se tiene en cuenta que es un campo donde, según Guerra Daneri (2000), existe una asunción de riesgos de magnitud desconocida y con trascendencia sobre bienes y derechos jurídicamente entrelazados como son la biodiversidad y la salud de los consumidores.

\section{LA PRECAUCIÓN DESDE LA PERSPECTIVA CIENTÍFICA.}

Como ya se ha visto, el nacimiento de la moderna idea precautoria está estrechamente unido a algunos científicos que propusieron la necesidad de prohibir la manipulación y fabricación de sustancias especialmente tóxicas. Aunque si seguimos a F.Sandback (1982) deberíamos aceptar que en la década de los setenta la comunidad científica se sentía muy incómoda cuando percibía las incertidumbres que se agazapaban en sus trabajos, pero a las que pocas veces podían dedicarse aun cuando pudieran comportar riesgos serios cuando no peligros especialmente graves. Y también cuando señalaba el papel que tenían los monopolios industriales de la química en la financiación de investigaciones que reforzasen las mismas incertidumbres, de manera tal que pudieran continuar utilizándose los argumentos que abogaban por la imposibilidad de tomar decisiones respecto la restricción de determinadas sustancias.

Vemos así como la relación entre la ciencia y la precaución adopta un carácter fundamentalmente social y político. Hasta el punto de condicionar el comportamiento paradigmático de la ciencia, que la lleva a profundizar en los temas que las estructuras hegemónicas consideran conveniente estudiar. Del mismo modo que también la orienta sobre lo que se debería relativizar o, incluso, menospreciar. Probablemente esta cuestión sea crucial a la hora de entender el proceso seguido por la ciencia -mejor deberíamos decir determinados científicos- en su esfuerzo por desarrollar sus líneas de investigación precautoria. Esfuerzo que no tuvo su reconocimiento hasta finales de los noventa. Vamos a ver a continuación, ni que sea de modo introductorio, tres aspectos clave que caracterizan el posicionamiento actual de la ciencia respecto de la precaución. El primero, el que se relaciona con los planteamientos metodológicos implicados en las incertidumbres; el segundo, su voluntad de dar respuesta a la situación mundial de crecimiento de los riesgos y peligros y; el tercero, la abertura de los procesos de investigación a la sociedad, particularmente aquellos grupos más directamente afectados por los problemas en estudio.

\section{La precaución en el marco actual de cambio científico: las incertidumbres como reto científico}

Asumir las incertidumbres a las que se enfrenta una investigación, y a las que no siempre se puede responder, es una necesidad cuando el científico empieza a asumir muchos aspectos de la complejidad implicada en su objeto de estudio. Esta es una experiencia que ha ido condicionando gran parte del devenir de la geografía contemporánea. Y sabemos por tanto que comporta ventajas 
pero también inconvenientes. Pero en cambio, es una experiencia bastante novedosa para otras disciplinas, todavía bajo la égida del neopositivismo o menos dadas a la autocritica. Pero la percepción de esta complejidad y de las dificultades que conlleva, tanto epistemológicas como metodológicas, es un reto que también se ha ido abriendo camino en la comunidad científica, tanto desde planteamientos más claramente sociales, como el que abrió Edgard Morin en su momento, como de otros investigadores procedentes de las ciencias físicas, como el mismo Illya Prigogine o Fritjof Capra entre otros. Este tipo de planteamientos, que insiste en la necesidad de abordar los temas desde una perspectiva de complejidad ha continuado hasta nuestros días, cuando los problemas socioambientales y de salud han continuado creciendo, conformando un marco de trabajo muy pertinente para experimentar y profundizar en algunos modelos y conceptos. Entre ellos el mismo de la precaución y la prevención en origen.

Como ya se ha comentado antes, el congreso de Wingspread en 1998 señaló un punto de inflexión a partir del cual la precaución pasa a ser un tema fundamental de la ciencia. Los participantes de aquel congreso escribieron a modo de conclusión de aquel congreso una declaración que constituye uno de los manifiestos científicos emblemáticos de esta nueva ciencia, que habría de ser metodológicamente diferente, al tiempo que se esperaba que fuera éticamente más responsable y exigente. Cuatro años más tarde, en 2002, un segundo congreso internacional sobre la precaución, organizado por el Lowell Center for Sustainable Production de la Universidad de Massachussetts ratificaba esta misma declaración. Vamos a detenernos a continuación en dos aportaciones de este segundo congreso que pueden ser especialmente útiles en relación a lo que estamos tratando.

La primera formulación que queremos destacar fue la que propusieron Gee y Stirling (2003, p.196), que sostenían que no todas las incertidumbres comportan el mismo tipo de práctica precautoria puesto que, en realidad, no todas las incertidumbres corresponden a los mismos niveles o estados de desarrollo del conocimiento, lógicamente heterogéneo y diferenciado al compás del proceso histórico de formación de las ciencias. Concretamente, distinguían hasta tres niveles distintos de conocimiento, cada uno con sus respectivas incertidumbres y posibles estrategias precautorias. En primer lugar, un nivel de conocimientos estructurado en datos suficientemente conocidos sobre situaciones probadas de riesgo, respecto a las cuales habría que aplicar la estrategia de la prevención en origen, con restricciones y prohibiciones específicas. Por ejemplo, la prohibición de fabricar, utilizar o estar sometido a substancias peligrosas, como el polvo de amianto, el polivinilo clorado, los ftalatos, las dioxinas y tantos otros compuestos persistentes. Un nivel o estado respecto al que no habría que hablar tanto de incertidumbres como de obstrucción de informaciones y estudios en la línea denunciada mucho antes por el ya mencionado Sandback. Seguiría después un segundo tipo de situaciones científicas más complejas de las que se dispone de una profusión de datos sobre los impactos pero sobre las que todavía existirían muchos interrogantes o incertidumbres. Nos encontraríamos aquí situaciones nuevas o relativamente nuevas, como por ejemplo las que está provocando el incremento de antibióticos en el ecosistema, que aconsejan la adopción de medidas de precaución preventiva, como serian por ejemplo, las concreciones legales de algunos estados europeos de la Directiva Europea sobre OMGs y que son relativamente restrictivas, o también la prohibición respecto al uso de piensos en la alimentación animal. Vendría finalmente una tercera situación caracterizada por un conocimiento relativo pero probable de los impactos y frente al que deberían impulsarse estrategias de precaución para anticiparse a los posibles riesgos y reducir los impactos ante posibles sorpresas. La mayoría de ellas en un contexto de complejidad extrema y alcance mundial para el cual no se tienen respuestas científicas, o no se tendrán al menos en un futuro asumible, que permitan resolver todas las incertidumbres, o al menos una parte razonable de las mismas. Y que correspondería a situaciones de peligro, como las denomina Beck (1994), que pueden derivar en verdaderas catástrofes y frente a las que, a causa de la magnitud de los impactos, no hay posibilidad real de control ni caben compensaciones. Piénsese, por ejemplo, en los dos accidentes nucleares de Txernòbil y Fukushima y la magnitud de la catástrofe tanto en las escalas 
local, regional y mundial.

La segunda aportación que queremos comentar es la de Crannor (2003). Este autor sostenía que la precaución conecta de manera muy estrecha con las nuevas corrientes de la ciencia porque permite reconocer las incertidumbres e incógnitas del trabajo científico como un objetivo específico de atención y trabajo dentro de un marco teórico, al tiempo que lo fuerza a situarse en el marco de la complejidad real. Lo que sería un planteamiento muy cercano al que hacen aquellos que consideran que la ciencia debería cumplir un papel anticipatorio, aportando información y propuestas a problemas y situaciones que pueden ir agravándose en un futuro más o menos cercano. Como sus colegas Gee y Sterling, este autor también piensa que hay que separar muy claramente las situaciones o casos sobre los que existe información fidedigna de aquellos otros donde lo que falta son datos empíricos, aunque sólo sea en algunos niveles de la investigación. Precisamente en este segundo tipo de situaciones donde afloran con más nitidez las incertidumbres. Las cuales pueden ir asociadas a un conjunto da factores causales que no son evidentes por distintas razones. Por ejemplo, que forme parte de un sistema de relaciones poco conocido, ya sea porque son acumulativas o bien porqué existe un periodo de latencia entre el momento inicial y el de la evidencia del impacto. En cualquier caso, hay que prestar atención a estos contextos de incertidumbre, especialmente cuando conectan con la dimensión ética y los valores implicados en la misma investigación.

Explicitar la conexión entre ética y práctica científica es muy importante en este nuevo contexto científico. Funtowicz -que había trabajado estrechamente con el filósofo británico J. Ravetz- señala que las incertidumbres forman parte ineludible de la ciencia, por lo que académicos, expertos e investigadores están obligados a considerar cuales son las preguntas e interrogantes, que se agazapan en cualquier tema que se esté estudiando. Las preguntas e interrogantes, que se transforman en incertidumbres cuando se trata de la aplicación del trabajo científico, no siempre son las mismas, pudiendo ocurrir dos cosas, no necesariamente independientes. Una, que estas incertidumbres vayan ganando protagonismo a remolque tanto del avance del conocimiento científico como de la gravedad de los impactos. Y dos, que no se pueda, o no se quiera, resolver las incógnitas con los instrumentos habituales de la ciencia. Lo que sitúa a la ciencia en una situación comprometida en unos momentos en que las implicaciones y consecuencias éticas de los problemas que se están estudiando pueden llegar a ser muy graves. Por ejemplo, las incógnitas que gravitan en torno a la política sobre los agrotóxicos en Brasil, un tema de gran trascendencia al que ya se ha hecho mención, y sobre el que existen numerosos interrogantes sobre la adecuación del modelo epidemiológico vigente, básicamente reduccionista y sin consideración por la complejidad de los procesos involucrados (AUGUSTO, 2012).

\section{Riesgos, peligros y vulnerabilidad}

Pero no sólo la complejidad y las incertidumbres explican el interés de la ciencia por la precaución. También las evidencias del día a día sobre los peligros socioambientales han contribuido a aumentar la atención por los planteamientos precautorios. Queremos detenernos en este adjetivo socioambiental del peligro porqué cada vez más los riesgos, peligros y catástrofes se producen en el contexto de una cadena de interacciones en el que los factores tecnológicos son progresivamente más importantes. Con las consiguientes responsabilidades éticas, que atañen a los actores sociales que los generaron y a la administración pública en su papel de garante del equilibrio social y la seguridad de las personas. Efectivamente esta es una situación que compromete en gran medida a la ciencia, tanto por las preguntas que se le formulan como por las respuestas que debe dar.

En un intento por acercarnos a esta responsabilidad de la ciencia en el terreno de las relaciones socioambientales hay dos conceptos que nos pueden servir de ayuda. Nos referimos al concepto de peligro y al de vulnerabilidad. Veámoslos con un cierto detalle.

Primero el concepto de peligro, fuertemente asociado al de riesgo y al de catástrofe. Como explicaba Beck (1994) hay que diferenciar los riesgos de los peligros, por cuanto los primeros 
comportan una posibilidad de previsión y gestión frente a los posibles impactos. Por tanto, los riesgos son un ámbito de trabajo con relativamente poca incertidumbre, aunque pueden existir condicionantes culturales y comportar consecuencias sociales muy graves. Lo que explicaría que esté empezando a adquirir protagonismo el concepto de construcción social del riesgo. Piénsese, por ejemplo, en las poblaciones pobres residentes en los lechos de inundación temporal de ríos y arroyos de las ciudades de muchos países latinoamericanos y el riesgo que corren ante fenómenos de inundación Una situación desgraciadamente común en Latinoamérica, y que ha sido estudiada en Fortaleza por Dantas y Lustosa (2009) y Queiroz de Almeida (2011) evidencia como un impacto relativamente probable y claramente físico comporta un conjunto de circunstancias y condicionantes sociales focalizado directamente a los segmentos más pobres de la población.

El peligro se diferencia del riesgo por diferentes razones. Quizás la fundamental desde la perspectiva de la precaución estriba en que en los peligros aumenta el número de incógnitas o incertidumbres, especialmente en lo que atañe a los daños, que pueden resultar más graves, por más tiempo y a más personas. Incluso hasta comportar verdaderas catástrofes respecto a las que los instrumentos de gestión y compensación son inadecuados o bien no existen. Lo que explica la actual preocupación por la implementación de medidas de apoyo e intervención en un campo de intervención desgraciadamente en ascenso. Y justifica, por supuesto, la necesidad de acciones precautorias.

Piénsese, por ejemplo, en los impactos del ciclón Katrina en la ciudad de New Orleans. Una catástrofe causada directamente por un fenómeno meteorológico pero cuya magnitud no puede explicarse si no es por circunstancias exclusivamente sociales. Entre ellas un conjunto de factores bien conocidos, como eran las condiciones de pobreza de una parte importante de la población de la ciudad, las dificultades para la evacuación y el deterioro de las infraestructuras de control hidráulico de la ciudad y las dificultades de evacuación (LE TRÉHONDAT; SILBERSTEIN, 2010). Pero también una serie de circunstancias no suficientemente estudiadas ni ponderadas, que atañen a diferentes escalas. Como más conocidas, pero todavía con un grado relativo de incertidumbres, las que tienen que ver con las interrelaciones entre las emisiones de gases de efecto invernadero y el calentamiento global que pueden alentar la virulencia de determinados fenómenos meteorológicos locales. Pero también otras indiscutiblemente sociales, que forman parte de toda una serie de riesgos sectoriales que se fueron generando al compas de la industrialización de la ciudad y las áreas circundantes y que repercutieron conjuntamente en un aluvión de aguas contaminadas que incluían metales pesados y compuestos organoclorados. Con especial incidencia en algunos barrios más pobres.

Los impactos del Katrina sobre la población conducen al segundo concepto que queríamos tratar, la vulnerabilidad,. Porque, efectivamente, los riesgos, los peligros y las catástrofes tienen un fuerte componente social, que se expresó tanto en el número de muertes y personas afectadas como en la gravedad del impacto y la imposibilidad o las dificultades para reponerse.

Inicialmente, el concepto de vulnerabilidad se utilizaba en la biología y la ecología. Y aunque en geografía hace ya tiempo que hablábamos de paisajes vulnerables, su introducción en las ciencias sociales ha sido más reciente. Podría pensarse que en un intento para plantear los problemas y las injusticias de los conflictos socioambientales con un lenguaje sociológica o políticamente más neutro que no la escueta desigualdad social ante el infortunio o las catástrofes. Los primeros estudios de este tipo se remontan a los inicios de los años noventa cuando se empezó a plantear la posibilidad de los impactos resultantes del calentamiento global por la subida del nivel mar.

De todos modos ha habido una evolución en la utilización de la idea de la vulnerabilidad. En parte a remolque del avance del conocimiento de los impactos del fenómeno del cambio climático y el calentamiento global en otros ecosistemas, como son, especialmente, los altiplanos en los Andes y el Himalaya, y también las de las zonas subdesérticas, como el Sahel en África. Actualmente, el concepto de vulnerabilidad se utiliza para referirse a propiedades o características de las personas, 
que las hace proclives a los impactos. Lo que conlleva que la vulnerabilidad tienda a centrarse en una serie de grupos o capas sociales, aunque puede llegar a afectar a toda la colectividad.

En cualquier caso, la vulnerabilidad ha pasado a tener un gran interés en la ciencia actual, especialmente cuando trata de fenómenos relacionados con riesgos y peligros socioambientales y obliga a plantear la complejidad de los fenómenos y circunstancias, especialmente cuando interaccionan entre unos y otros y dejan su huella en la población.

Una vez más hemos de referirnos al los agrotóxicos al pretender mostrar un ejemplo de vulnerabilidades sociales a un problema tecnológico que se expresa en la forma física de la contaminación. Rigotto (2011a i b) ha desarrollado un amplio y riguroso trabajo de investigación sobre el tema explicando las vulnerabilidades extremas de los trabajadores agrícolas, así como de los habitantes rurales, particularmente los niños, en las regiones donde se utilizan masivamente estos productos. Desafortunadamente, la literatura sobre los impactos de los agrotóxicos incluye muchos otros lugares y países. Por ejemplo, la población campesina del valle del Yaqui en Sonora (México), un valle de agricultura intensiva, ha sido objeto de análisis en diferentes investigaciones sobre vulnerabilidad. Una de ellas, la de Turner, Matson, Kasperson y Kasperson (2002) llegó a la conclusión que la vulnerabilidad resultaba condicionada por procesos que interactuaban entre sí, fundamentalmente el calentamiento global y el cambio del nivel del mar -en lo que se refiere a riesgos físicos- y la globalización del mercado, la fluctuación del peso, la urbanización y la emigración en lo que atañe a riesgos asociados a procesos sociales. También disponemos del estudio de Gillette (2003) sobre los impactos de la utilización de tóxicos en las prácticas agrícolas en los niños y que se traducían en un deterioro del desarrollo intelectual y escolar, Y que concluía en la necesidad de adoptar estrategias de prevención en origen si se quería reducir el riesgo de los niños a quedar fuertemente restringidos a la educación y otras expectativas de futuro en su vida adulta o, en resumen, a enfermar de manera grave.

No quisiéramos terminar este apartado sin referirnos a un desarrollo reciente de la vulnerabilidad. Se trata, concretamente de la vulnerabilidad a un fenómeno claramente social, y que se expresa en la idea de la crisis energética, entendida ésta como reducción de los hidrocarburos y el consiguiente aumento de precios, especialmente de la gasolina. Lo que sitúa a la vulnerabilidad en un contexto claramente socioecológico, tal cual es el agotamiento del recurso del petróleo, el calentamiento global, etc. Y que quizás podría tener su antecedente en el trabajo ya citado de Turner y colaboradores (2002) cuando planteaba el papel del urbanismo como generador de vulnerabilidad social. En este contexto también podemos referirnos a los estudios de Dodson y Neil (2007) sobre la vulnerabilidad social urbana ante la crisis energética en las ciudades australianas, que cifraba la vulnerabilidad entre un 40-50 \% de la población. Y también al de Peña (2010) para el área metropolitana de Barcelona, con unos resultados también muy preocupantes sobre la vulnerabilidad de algunos municipios, a consecuencia de las altas tasas de paro, la escasez de trabajo local y la fuerte dependencia al transporte privado.

\section{La relación entre ciencia, participación ciudadana y la ética de la tierra}

Hace ya bastante tiempo (ALIÓ, 1999) tuvimos la primera oportunidad de referirnos a Funtowicz por sus aportaciones sobre la dimensión ética de las problemáticas ambientales. Y habíamos recurrido a este autor porqué pensábamos que aportaba un interesante marco teórico que justificaba los esfuerzos que estábamos dedicando entonces a las metodologías participativas. Desde entonces hasta ahora parece que lejos de haberse diluido, lo que decíamos antes se hubiera reforzado todavía más, tanto por la insistencia de los nuevos movimientos sociales en el posicionamiento activo y participativo, como del desarrollo de la cultura ambiental y precautoria y del incremento de las problemáticas medioambientales y sus repercusiones entre la población. Porqué, en suma, las incertidumbres implicadas en el estudio de fenómenos y problemas que afectan a las personas son una buena razón para justificar la participación de la población implicada en el desarrollo de la 
práctica científica. Tanto más imprescindible cuanto mayor es el riesgo o el peligro y más numerosas son las incertidumbres de la ciencia cuando se plantea la resolución, o la intervención en las problemáticas o las realidades en estudio.

Muchos científicos han tratado este tema, aunque probablemente sea Funtowicz (1994) quien lo ha explicado más acertadamente. Las relaciones entre la ciencia y la participación también han inspirado numerosos congresos. Entre ellos la Conferencia Internacional sobre Transdisciplinariedad y Relaciones entre Ciencia, Tecnologia y Sociedad (Transdisciplinarity: Joint Problem-Solving among Science. Technology and Society. Internatiuonal Transdisciplinarity Conference 2000) celebrada en Zurich, en los mismos años en que hemos visto a Cranor, Gee y Sterling proponiendo la adopción de metodologías participativas en los estudios que requiriesen estrategias precautorias.

Lo que nos lleva a los momentos actuales, cuando la situación de emergencia ambiental, tal como viendo siendo definido por la Organización de las Naciones Unidas para la Educación, la Ciencia y la Cultura (GIL; VILCHES, 2009) hace todavía más necesarias la precaución y las metodologías de participación. Quizás tan sólo dos ideas para explicar brevemente la relación entre participación y precaución por un lado y la emergencia ambiental por el otro. La primera idea, el hecho que la población presuntamente implicada en los problemas ambientales ha dejado de ser exclusiva de las personas afectadas en las escalas local y regional. Efectivamente, hoy en el mundo, muchos y graves problemas socioambientales están afectando también la escala global -desde el calentamiento global a la deforestación, pasando por la contaminación causada por las emisiones de órgano clorados y las radioactivas- situando por tanto la necesidad de participación en un marco universal. Lo que conduce a plantear nuevos requisitos y condicionantes para las metodologías de participación. La segunda cuestión que queríamos plantear se refiere a los problemas de salud de los ecosistemas que se han heredado a causa de los impactos generados en el pasado, pero que continúan produciéndose en la actualidad. Y que lleva a hablar de un fenómeno estructural de contaminación -y degradación medioambiental- que además del calentamiento global, incluye a la contaminación radioactiva y por emisiones de partículas órgano cloradas, como los bifenilos policlorados, las dioxinas y los furanos. Es precisamente en relación con este último tipo de contaminación que está emergiendo la idea de que se estaría actualmente en una nueva situación de precaución, porqué las necesidades actuales de intervenir precautoriamente están provocadas no sólo para reducir en origen los impactos de las actividades antropogénicas actuales, sino también por los que se generaron en el pasado pero que no fueron contemplados en su momento.

Por consiguiente, es muy probable que los planteamientos precautorios sean uno de los caminos de la ciencia actual en su proceso para renovarse y desempeñar el papel que les está pidiendo la sociedad. Por supuesto que la aceptación de la complejidad y las incertidumbres que conlleva contrasta con los planteamientos anteriormente vigentes en la comunidad científica, resguardada en la creencia que se podía encontrar soluciones para todo, incluso para los problemas medioambientales. Desde entonces hasta ahora, sen embargo, ha ido ganando credibilidad la idea que la resolución de los problemas no era simplemente una cuestión de encontrar la solución técnica adecuada, sino que también habían que cambiar muchas cosas de la misma cotidianeidad humana, desde los procesos extractivos y de producción a los de consumo, y también con implicaciones en la misma práctica científica. Entre ellas la participación de la población.

\section{EMERGENCIA Y CONSTRUCCIÓN SOCIAL DE LA PRECAUCIÓN}

Hasta aquí toda una serie de ideas y consideraciones que nos llevan a entender el planteamiento precautorio en un marco complejo de relaciones sociales, expresadas en dos elementos sociales tan importantes como son la ciencia y la legislación. Sabemos, sin embargo, que estos mismos desarrollos científico y jurídico no hubieran sido posibles sin una interrelación estrecha con las expectativas e intereses de una sociedad progresivamente más preocupada por los problemas am- 
bientales y de salud. Por este motivo vamos a dedicar este apartado a la implicación de la población en el desarrollo precautorio. Con este objetivo hemos divido las páginas que siguen en dos grandes apartados: uno introductorio en primer lugar, que pretende tan sólo ofrecer una breve panorámica sobre el desarrollo de implicación ciudadana para con la precaución; y el segundo, consistente en la explicación de una serie de ejemplos que ayuden a conocer y entender mejor algunas de las modalidades principales del protagonismo ciudadano.

\section{Desarrollo de la idea precautoria en los movimientos sociales contemporáneos}

Al empezar este artículo comentábamos que el planteamiento precautorio se remonta a finales de los años cincuenta y mediados de los sesenta en el siglo pasado. Con ya más de medio siglo de experiencias, puede hablarse por tanto de un proceso en el que podríamos aventurarnos a distinguir entre una primera etapa, caracterizada básicamente por movimientos reivindicativos y de oposición a las actividades generadoras de impactos y respecto a las cuales debería aplicarse el principio precautorio, y una fase actual, en la que las condiciones de precariedad y peligro socioambientales hacen igualmente necesaria la reivindicación pero que se complementa y diversifica con acciones de carácter propositivo, que comportan acciones respaldadas directamente por los actores sociales.

De hecho, estas dos fases se corresponden con el proceso de formación y desarrollo de los movimientos sociales contemporáneos. Concretándose en un primer momento con el periodo de formación del movimiento ecologista clásico, reivindicativo y de denuncia del aparato tecnológico-industrial, y en alianza con los movimientos feminista y pacifista por los intereses antinucleares comunes. Al que siguió una segunda fase, más compleja a medida que el interés medioambiental iba extendiéndose más allá de los círculos ecologistas, se hacían evidentes los obstáculos para implantar la legislación precautoria y se iba tomando conciencia de la necesidad de pasar directamente a acciones propias e independientes. Probablemente, esta tendencia más reciente podría definirse como una forma de expresión del fenómeno sociológico ambiental contemporáneo, a caballo entre las nuevas sociedades urbanas postmodernas, progresivamente preocupadas por calidad ambiental y la salud pública y el desarrollo de las corrientes de la ecología profunda, que ya fuera definida por Naess (1986 y 1989) como una tendencia del ecologismo que no trataba tan sólo de denunciar sino de vivir de manera acorde con lo que estaba reivindicando. De este modo, en la última década del último siglo, ya en el marco de la globalización, ha ido conformándose las nuevas corrientes ambientalista, habitualmente como transformaciones de tendencias existentes, si bien que normalmente imbricadas veces con los nuevos movimientos sociales. Que asumen propia la preocupación ecológica y que se refuerzan entre sí en todo el mundo.

Recientemente, hemos tenido la oportunidad de investigar los manifiestos y declaraciones para la protección medioambiental de la sociedad civil catalana (ALIÓ, 2011; JORI, 2011) que nos ha permitido identificar la secuencia de un proceso en dos fases. Concretamente, se ha podido observar que la cronología de estos escritos desde principios de los años setenta en el siglo pasado hasta la actualidad permite identificar la evolución desde un primer ciclo de manifiestos, redactados en su mayoría por el movimiento ecologista antinuclear, a otro gran ciclo actual caracterizado por la colaboración entre grupos ecologistas y asociaciones y colectivos sociales, con intereses temáticos heterogéneos pero unidos por la misma finalidad de protección de la naturaleza y el territorio.

En resumen, parecería que puede afirmarse que la precaución, desde sus orígenes hasta la actualidad, forma parte de un proceso histórico de construcción social de la cultura sobre la protección medioambiental referida a las relaciones entre la sociedad y la naturaleza. Tanto hace sesenta años, cuando emergió el peligro radioactivo, hasta la actualidad, en unos momentos en que se está haciendo patente la necesidad de ampliar las estrategias precautorias más allá de medidas precisas destinadas a prevenir en origen impactos ambientales concretos. Y que supone entre otras acciones, el robustecimiento de los ecosistemas como factor de estabilización planetaria futura, el establecimiento de un sistema de alertas sobre los riesgos y peligros ambientales futuros asociados a lugares 
concretos, la reivindicación de nuevos derechos humanos, incluido el derecho a la participación activa en la toma de decisiones relacionadas con la salud y el medio ambiente, y por supuesto, el de actuar de manera precautoria. (Raffensperger et alter, 2011).

Ejemplos y experiencias ciudadanas: De los residuos a la alimentación y la protección de la naturaleza

Siguen a continuación cuatro casos que pueden servir de ejemplo sobre como la ciudadanía se implica en actividades de gran trascendencia en procesos precautorios.

Las iniciativas ciudadanas para la reducción de residuos. Las iniciativas ciudadanas para la prevención en origen de la contaminación conforman el primer núcleo de acción reivindicativa y de oposición dentro del que empezó a germinar la idea de la precaución. Anteriormente, ya hemos destacado el papel de los fundadores de la ciencia del ecologismo contemporáneo, cuando empezaron a establecer las bases científicas de la prevención en origen. Las cuales, a su vez, daban soporte racional y argumentativo al renovado movimiento ecologista que, desde los años sesenta en el siglo pasado, empezaba a fraguarse en base a un triple frente: el primero, la oposición a la energía y las pruebas nucleares; el segundo, la critica a la industria y manipulación de sustancias tóxicas y la crisis de los residuos; y el tercero, la conciencia de las desigual distribución de los impactos tecnológicos, ya fueran de la industria química o nuclear.

De este modo apareció la idea de que debería prohibirse la fabricación y manipulación de procesos tecnológicos peligrosos para la salud y el medio ambiente. Dando alas a las movilizaciones contra la construcción de grandes instalaciones de tratamiento finalista que empezaron a surgir desde los sesenta en las regiones más ricas y desarrolladas, y que se han extendido actualmente en todo el mundo a remolque de la difusión del modelo económico del consumo y la estructura desigual mundial. Nosotros mismos, en la investigación a la que nos hemos referido más arriba (Alió, 2011), hemos constatado la emergencia del concepto de la precaución y de la prevención en origen en los manifiestos para la protección ambiental en Catalunya en 1987, antes que estos mismos conceptos fueran desarrollados en la legislación catalana. Otros autores, como los geógrafos Gerrad y Simpson (1995), habían destacado también desde principios de los noventa, la capacidad de las movilizaciones contra este tipo de instalaciones de constituirse en un marco social favorable para el desarrollo de las nuevas culturas ambientales, incluida la idea de la precaución y la de responsabilidad. Conclusión que, por nuestra parte, podemos confirmar en base a las investigaciones que hemos realizado sobre el mismo tipo de movilizaciones en Catalunya. (ALIÓ, 2008; JORI, 2009)

Con todo, el avance de la precaución ha sido hasta ahora lento y circunscrito a sectores muy concretos determinados, con tendencia a desarrollarse donde existe mayor sensibilidad ambiental. Efectivamente, las diferencias geográficas en la aplicación de criterios precautorios evidencia grandes desigualdades territoriales, las cuales, cuando se estudian en detalle, permiten identificar una clara interacción con sociedades ambientalmente implicadas. Hace algunos años tuvimos la oportunidad de investigar este tema centrándonos en la gestión de los residuos municipales y tomando como base los municipios de algunas ciudades y áreas metropolitanas de Europa, Estados Unidos y Catalunya. Con resultados contundentes sobre las diferencias existentes entre los municipios en función del mantenimiento de una política finalista o bien la transición a una política precautoria. La cual, por supuesto, estuvo estrechamente relacionada con la capacidad de los actores sociales para influir en la política local a través de las redes personales y asociativas y también a través de la formulación proyectos alternativos que estructuraban los instrumentos de gestión hacia la prevención. Actualmente, estos municipios conforman más de un centenar de localidades con porcentajes de recuperación de residuos que oscilan entre el $45 \%$ y el $82 \%$. Unos resultados claramente diferentes a la mayoría de municipios catalanes, con porcentajes de recuperación entre el 15\% y el 33\%. (ALIÓ, 2008).

Antes de cerrar este apartado sobre las acciones ciudadanas para la prevención de residuos, permítasenos aportar dos últimas experiencias. La primera, el crecimiento del movimiento mundial 
conocido como Residuo Cero, que se inició ya en los ochenta en San Francisco de la mano de la población concienciada ambientalmente de la ciudad y su área metropolitana y que se ha difundido hasta hoy para constituirse en un modelo alternativo destinado a favorecer las estrategias precautorias en la generación de residuos. Existen multitud de experiencias en el mundo que podrían servir de ejemplo sobre como los altos índices de recuperación de residuos se relacionan con acciones ciudadanas para introducir estrategias de prevención en sus modos de vida y en la política pública local

Y la segunda, un conjunto de iniciativas recientes que podrían estar apuntando a una nueva generación de acciones públicas para prevenir en origen emisiones tóxicas en servicios públicos y actividades económicas cuyo origen también se sitúa en el marco de la presión y la implicación de la población. La primera de ellas, la prohibición en la ciudad de Los Ángeles de utilizar determinadas sustancias en los colegios públicos, especialmente productos de limpieza que se venían usando en las escuelas y que contenían pesticidas (Integrated Pest Management Policy, 1998). Prohibición que fue seguida poco más tarde por la ciudad de San Francisco, ya dentro de un marco legal más complejo que argumentaba específicamente la necesidad de aplicar el principio de la precaución en las actividades y edificios públicos, especialmente en los de las escuelas (WHITE PAPER, 2003), que sirvió de base para redactar una ordenanza que obligaba a contemplar la precaución para introducir el criterio precautorio en las escuelas del área metropolitana de la ciudad. Por otra, y en relación con las actividades económicas, existe también múltiples iniciativas impulsadas desde la sociedad civil, básicamente corporaciones de profesionales. Por ejemplo, las actuaciones de la Science and Environmental Health Network -una prestigiosa asociación de profesionales y científicos en salud pública- para introducir en 2009 el criterio precautorio en los distintos sectores de la estructura económica, desde la agricultura a los servicios hospitalarios. También en Europa existen múltiples experiencias de este tipo. Por ejemplo, en Barcelona, las de la Fundació Catalana per la Prevenció de Residus, vinculada a asociaciones ciudadanas y que ha impulsado múltiples campañas en las escuelas, tiendas y supermercados y otros tipos sectores económicos. Y también desde el ámbito de los colegios profesionales y universidades los que vienen impulsándose en Dinamarca desde inicios de los noventa (FORMAN; JORGENSEN, 2005, JORGENSEN, 2011).

La precaución en el mundo urbano. Aunque las acciones para la reducción de residuos son trascendentales en la sociedad contemporánea, también existen otros ámbitos donde es imprescindible intervenir. Se puede recurrir a la larga tradición de experiencias, teorías e información que han impregnado los proyectos de transformación ecológica de las ciudades y que, ya fuera explícita o implícitamente, tenían a la precaución entre sus planteamientos.

Hay que reconocer, sin embargo, que en muchos pueblos y ciudades la política oficial se encuentra prisionera todavía en el modelo del uso del suelo que refuerce el crecimiento económico. Precisamente en unos momentos que las estructuras de la globalización económica presionan todavía aún más sobre los recursos naturales y la redistribución social, haciendo todavía más evidente el papel que podrían desempeñar las ciudades en procesos de desarrollo basados en otros roles y características del espacio local. Por todo ello se entiende que esté emergiendo actualmente un nuevo movimiento social, de carácter profundamente urbano, que reivindica la resolución de los problemas socioambientales ligados al crecimiento de las ciudades y al desarrollo del capitalismo. Este movimiento, de carácter transversal, incorpora múltiples segmentos de la vida asociativa moderna, incluidos los colectivos ecologistas, unidos todos ellos por los mismos objetivos de denuncia de expoliación socioambiental y de protección ambiental. Incluyendo a la precaución tanto en sus reivindicaciones como en sus pautas de acción, que se concretan muchas veces en un marco de realizaciones que conectan y se refuerzan entre sí.

A modo de ejemplo quisiéramos aportar la experiencia de un congreso organizado en 2007 por organizaciones de la sociedad civil barcelonesa con el objetivo de debatir y proponer acciones que podía ejercer la ciudadanía barcelonesa en la situación de cambio climático. En este congreso se realizaron cuatro sesiones de deliberación entre los asistentes que tenían el objetivo de proponer 
las acciones a proponer por el congreso para reducir el impacto de la ciudad en el cambio climático. Puede ser útil explicar que muchas de estas acciones incorporaban un fuerte carácter precautorio relacionado, a su vez, con la cotidianeidad y los comportamientos de la población. Por ejemplo, casi la mitad de las acciones tenían un fuerte carácter cultural, relacionadas con la necesidad de explicar y difundir la responsabilidad ética y ambiental de muchas de las conductas y hábitos de los habitantes de las ciudades en la generación de impactos ambientales y la manera como afectan a las personas. También hubo propuestas para el mundo académico. Destacando las que proponían incluir en los planes de estudio contenidos docentes sobre las consecuencias sociales y ambientales de determinadas formas de explotación de recursos y de manipulación tecnológica, en especial en los de las carreras físicas y tecnológicas. Ampliando un poco más el contenido de estas propuestas, se podría añadir que un grueso importante -más de la cuarta parte de las propuestas- trataban sobre la manera de impacto de los procesos de producción y tecnológicos en el cambio climático. Reducción que se basaba, por supuesto, en la reducción del consumo de determinados productos, comportando la aplicación de estrategias de prevención en origen en la vida cotidiana. Estrategias que, a su vez, podían ser promovidas desde las redes sociales. (ALIÓ, 2008).

Este carácter activo y de implicación ciudadana en una realidad socioambiental progresivamente más compleja y con más peligros de origen tecnológico constituye uno de los rasgos de este movimiento ciudadano que ya hemos comentado de carácter muy heterogéneo y temáticamente transversal. Ello se expresa, por ejemplo, en el florecimiento de iniciativas cooperativas de consumo que atañe diferentes objetos, la alimentación preferentemente, pero que también se expande hacia otros frentes, como los servicios o el turismo, con la pretensión de organizar estructuras de mercado local, a veces regional, de base ciudadana colapsando de este modo las macro estructuras del mercado global y reduciendo los impactos derivados de las largas distancias.

La necesidad de reducir los costes económicos y ambientales de las largas distancias ha contribuido a consolidar otras líneas de acción con las que se relacionan pero que se pueden presentar de manera diferenciada. Una de ellas, la de las agriculturas urbanas, influenciada muchas veces, pero no siempre, de la tradición de la permacultura y en la situación actual de crisis económica encuentra un contexto favorable de difusión. Pensemos, por ejemplo, en las iniciativas de las transitions towns, en expansión en todo el mundo, incluso en algunas grandes ciudades y áreas metropolitanas (SCOTTI, 2011). O también, los huertos urbanos, también en franca expansión en muchas ciudades del mundo y que, contribuyen, todos ellos, a prevenir en origen muchos impactos relacionados con los agrotóxicos y el transporte para el abastecimiento alimentario al tiempo que fortalecen el conocimiento de la población y su sentido de comunidad frente a la alineación globalizadora.

Los comedores escolares ecológicos. Las comunidades escolares constituyen el tercer tipo de experiencias que queríamos comentar ya que aun pareciendo muy sectoriales y focalizadas en el tema alimentario y educativo de los niños, tienen una gran capacidad de reforzar procesos que trascienden a la precaución y la salud proyectándose al conjunto del territorio, y en particular a la agricultura ecológica. Hay iniciativas de este tipo en muchos países. En Brasil, por ejemplo, se desarrollaron al compás de la búsqueda por unir la alimentación infantil en las escuelas públicas con el proyecto económico de desarrollo de la pequeña agricultura familiar. No tan condicionada a la utilización de compuestos químicos tóxicos, cuando no totalmente libre de ellos (GARCIA; GONDIM; SILVA, 2011). En otros lugares, como por ejemplo en Catalunya, están estrechamente asociados al interés por ofrecer en las escuelas una alimentación saludable con origen en la agricultura ecológica. También los orígenes fueron diferentes en Catalunya, puesto que nacieron al compás de la preocupación de las asociaciones de padres y madres de las escuelas por la calidad de los alimentos que se ofrecían en los comedores escolares, que son pagados por las familias. Poco a poco, desde principios de siglo, el interés de los padres empezó a incluir también preguntas por la composición y la manipulación de los alimentos y la posibilidad que pudieran llevar sustancias tóxicas asociadas. Lo que llevó a plantear, seguidamente, una reflexión crítica sobre las prácticas 
agrícolas de las cuales procedían los alimentos y de las enfermedades que podían llegar a generar entre la población infantil, especialmente vulnerable a los agrotóxicos. De este modo, en un momento de especial sensibilidad por la calidad de vida y la salud pública, el empeño por hacer más saludables los comedores escolares se vio reforzado por las posibilidades de comprar alimentos procedentes de la agricultura ecológica. Y que se vieron reforzadas cuando nuevas generaciones de ecoprofesionales y también algunas instituciones públicas empezaron a ofertar instrumentos de conexión entre los comedores escolares y las explotaciones de agricultura ecológica. Es decir, entre la oferta y la nueva demanda de las escuelas, necesitada de alimentos cercanos de calidad.

C. Raffensperger (2011), de la Science and Environmental Health Network anteriormente citada, sostiene que una de las medidas precautorias más importantes que pueden realizarse actualmente en las grandes ciudades y las aglomeraciones industriales, con altos niveles de contaminación atmosférica, consiste precisamente en proteger a la población más vulnerable, especialmente a los niños, con una alimentación saludable, proveniente de la agricultura ecológica, lo que permite prevenir en origen muchas enfermedades causadas por la presencia de las sustancias tóxicas presentes en alimentos procedentes de la agricultura industrial. Lo que situaría a los comedores escolares en una de las avanzadillas del movimiento por la alimentación saludable y la transformación agrícola ecológica.

En un intento por ilustrar mejor las características y composición de este movimiento, pasamos a ofrecer a continuación unos datos a partir de un primer sondeo realizado exclusivamente para España. En primer lugar una poca información sobre su expansión, que hemos podido corroborar para Andalucía, Euskadi, Murcia, y Catalunya. Aunque en estos momentos de la investigación no hemos podido acceder a datos desagregados por escuelas para áreas homogéneas, podemos avanzar que los comedores escolares ecológicos se encuentran en los dos niveles infantiles: las guarderías y las escuelas de enseñanza básica obligatoria. Y que se localiza tanto en áreas rurales como urbanas, aunque no se dispone información del total de escuelas implicadas. Tan sólo de manera muy aproximada, podría aventurarse una cifra cercana a las 500 escuelas en Catalunya.

En cambio, disponemos de información más detallada sobre las estructuras organizativas de este sistema de relaciones entre escuelas y agricultores. En Catalunya pueden distinguirse hasta tres modalidades. La primera consiste exclusivamente en una forma de coordinación muy simple, entre unos pocos productores agrícolas ecológicos y una sola escuela, todos ellos próximos entre sí. La segunda modalidad ya es más compleja y la coordinación se ejerce desde las instancias públicas. Concretamente el Consell Comarcal, un organismo oficial para los municipios de cada comarca, que se responsabiliza de establecer las relaciones entre los productores agrícolas ecológicos de la zona y las Asociaciones de Padres y Madres que, a su vez, son las que coordinan los comedores escolares en las respectivas escuelas. Existe también, un tercer tipo organizativo más complejo que se estructura básicamente, aunque no exclusivamente, en redes. Este tercer tipo surgió recientemente en torno a DINA'M , pequeña empresa de servicios ecológicos que ayuda a poner en relación las escuelas con los productores agrícolas y ganaderos ecológicos en una central de compras de la que pasan a formar parte las mismas escuelas. Esta tercera modalidad, que también contó con el soporte público en la fase inicial, está empezando a extenderse en toda Catalunya desde el momento en que se articuló con un nuevo proyecto denominado SAVIAE, consistente en una plataforma telemática que coordina la difusión comercial de la producción integrada ecológica en toda Catalunya.

La protección de la naturaleza como medida precautoria. Pero no sólo se encuentran iniciativas de precaución en los espacios urbanos. También en los espacios naturales se desarrollan múltiples actividades que suponen, en la práctica, iniciativas de precaución. Se trata de acciones que, aún cuando se realizan en ecosistemas naturales de calidad, trasciende normalmente el planteamiento estrictamente conservacionista. Estos planteamientos precautorios en ecosistemas naturales de calidad son habitualmente complejos, incluyendo medidas de distinto signo, también los factores sociales, que se superponen y refuerzan entre sí como las únicas posibilidades de supervivencia 
o de preservación de la calidad ambiental. Entre los autores que han tratado este tema, García (2004) sostiene que estos lugares son intersticios del sistema global, mejor dicho del ecosistema mundial, que todavía no se han visto excesivamente afectados por el error tecnológico y que por tanto, conforman áreas y lugares desde los que dicho error puede ser contrarrestado.

Hace algunos años tuvimos la oportunidad de colaborar en una investigación sobre infraestructuras del agua en comunidades artesanales del litoral de Ceará . Esta investigación pretendía aunar los objetivos sociales de soporte a las sociedades artesanales y comunitarias con los objetivos ambientales -la preservación del acuífero y el ecosistema costero, desde un planteamiento precautorio y de participación de la población local. Cuando tuvimos la oportunidad de empezar a trabajar en el proyecto, la Universidad Federal de Ceará ya había iniciado algunas actividades preparatorias en las que también participaba la población local.

Concretamente, el proyecto había empezado centrándose en la dotación de pequeñas plantas de depuración de aguas residuales unifamiliares, con el objetivo de impedir la contaminación del acuífero que a su vez proporcionaba las aguas potables a la población. Al inicio se trataba de unas muy pequeñas plantas, construidas por los mismos habitantes de las casas bajo la tutoría del Instituto EcoVilas do Cerrado. Esta primera experiencia fue extendiéndose paulatinamente al resto de comunidades del término municipal. Al tiempo que otras iniciativas, la captación y almacenaje de agua de lluvia primero, seguidas por la educación ambiental y la puesta a punto de prácticas para la prevención de residuos en origen iban añadiendo complejidad y ambición al proyecto. Desde inicios de esta década el proyecto empezó a difundirse en forma de proyectos piloto a otros municipios del mismo litoral y también del sertao de Ceará.

A destacar que se trate de un proyecto enteramente asumido por las comunidades interesadas. Hay dos circunstancias que permiten entender su implicación. Por un lado el hecho que sea un proyecto considerablemente económico que puede ser asumido por la población local ya que los habitantes de las casas son los que se encargan del trabajo de construcción de las fosas de bioremedaçao, al tiempo que las organizaciones no gubernamentales que están operando en la región costean el gasto del material. También la comunidad se encarga del seguimiento de las instalaciones con la ayuda de la misma universidad. Pero también por otro lado hay que tener en cuenta que la salubridad del agua potable, que se capta del mismo acuífero, y de la que depende la salud de los habitantes, está básicamente condicionada a esta acción de prevención en origen.

Hay que decir al respecto que al inicio del proyecto también se habían considerado otras dos posibilidades para la depuración del agua. La primera consistía en acogerse a los planes del gobierno de Brasil para la construcción del alcantarillado y la conducción de las aguas residuales a una planta centralizada de depuración. Dicha planta debía basarse en el sistema de lagunas, pero suponía una opción casi impracticable a causa de los costes y las condiciones topográficas del lugar. La segunda posibilidad radicaba en desarrollar el método SODIS, muy extendido en el litoral cearense, y que consiste en la exposición al sol del agua extraída del acuífero dentro de botellas de plástico, fabricadas mayoritariamente con vinilo-policlorados, con el siguiente riesgo derivado de la formación de organoclorados durante el período de exposición al sol.

\section{CONCLUSIÓN}

Hasta aquí, en este apartado final, una serie de experiencias que ilustran de manera muy clara la complejidad de procesos y acciones sociales que promueven actualmente la precaución. Y que también nos muestran como el mundo científico puede colaborar en este proceso considerando distintas opciones tecnológicas, tal como explicaban Gee y Sterling (2003) sobre la necesidad de sondear distintas posibilidades tecnológicas con las personas afectadas cuando se plantea la posibilidad de tomar una decisión precautoria.

Durante décadas, de hecho desde los inicios de ciencia contemporánea, la geografía se ha 
interesado por el impacto y las interrelaciones entre la sociedad y la naturaleza. Y muy en particular por aquellas relaciones que se derivaban de interacción con elementos antropogénicos. Buena muestra de ello se encuentra en los contenidos de las geografías agraria y urbana, centradas en los procesos que explican las morfologías de estos espacios. Que, a su vez, se complementan con los modelos sobre el uso de los espacios, basados en lo que denominamos factores locacionales, asociados a las rentas económicas y a la especialización productiva y que resaltan el papel de la transformación de los espacios mediante la introducción de todo un conjunto tecnológico que han ido conformando campos y ciudades desde la revolución industrial a lo largo de un proceso que se ha ido incrementando y consolidando hasta nuestros días.

Este artículo, en cambio, ha querido resaltar el papel de toda una serie de factores aparentemente menores, de poca incidencia morfológica, y que son tan humildes como hasta el punto de poner la atención en el no hacer. Y con ello hemos querido traer a reflexión la idea que la geografía de nuestro tiempo debería profundizar en los factores que subyacen a la actividad humana con el objetivo de plantearse críticamente el orden de las maneras dominantes de relacionarse con la naturaleza. Estamos en una fase en que hay cada vez más personas que buscan una manera de modificar este orden y reclaman a la política, y los instrumentos jurídicos, que avalen esta búsqueda de un nuevo tipo de relaciones socialmente más justas y más en equilibrio con la naturaleza. En este contexto, la ciencia también empieza a posicionarse respecto esta realidad, empujando una serie de transformaciones que incumben directamente a los objetivos de la misma ciencia, incluyendo la adopción de metodologías de investigación participativas, el reconocimiento de las incertidumbres y también que deben darse respuesta a problemas, a veces muy graves, para los que no existen soluciones supuestamente objetivas. Estamos hablando, por tanto de una tendencia de cambio paradigmático, y aunque la precaución por ella misma no tiene este poder de cambio, sí que forma parte de toda una serie de procesos más complejos que parecen conformar nuevos panoramas para la ciencia.

\section{BIBLIOGRAFÍA}

ALIÓ, M. Àngels. Contaminació i Societat. Barcelona. Universitat de Barcelona, 1999. 148 p.

ALIÓ, M. Àngels. La paradoxa ambiental urbana: aproximacions a la formació de les noves cultures ambientals des de la crisi dels residus. En: ALIÓ, M À.; JORI, G. (Eds). Les sociertats urbanes davant la reforma ambiental. Visions i propostes al voltant de la sostenibilitat. Universitat de Barcelona, 2011. p. 129-150. ALIÓ, M. Àngels. Ciència i Societat davant la crisi energética: Experiències i Propostes de la ciutadania de Barcelona., Una sola Terra. Barcelona. Diputació de Barcelona, 2008, octubre de 2008. p.45- 54

ALIÓ, M. Àngels. La difícil transición hacia la prevención. Una visión desde el análisis de las políticas ambientales sobre los residuos. Scripta Nova, Barcelona, vol.12, n.270, 2008. http://www.ub.edu/geocrit/ AUGUSTO, Lia Giraldo da Silva. Agrotóxicos: nuevos y viejos desafíos para la salud colectiva. Salud Colectiva. Lanús: 8, n. 1, 5-8. 2012. http://www.scielo.org.ar/scielo.php?script=sci_arttext\&pid=S1851$-82652012000100001 \& \operatorname{lng}=$ pt\&nrm $=$ iso $>$. ISS

BECK, Ulrick. La sociedad del riesgo. Barcelona, Editorial Paidós. 1994. 400 pp.

CAMERON, James; O'RIORDAN, Timothy (Eds). Interpreting the Precautionary Principle. London: Earthscan, 1994. 321 pp.

CARSON, Raquel. Silent Spring. Boston: Houghton Mifflin, 1962.

COMMONER, Barry. The Closing Circle: Nature, Man, and Technology. New York: Knopf, 1971. 326 pp.

COMMONER, Barry. Making peace with the planet. New York : Pantheon, 1990. 293 pp.

COMMONER, Barry. Science and Survival. New York: Viking, 1966. 150 pp.

CRANOR, Carl F. What could precautionary principle be? Research for Early Warnings and a better future. En: TICKNER, J.A. Precaution, environmental science, and preventive public policy. Washington, Island Press, 2003. p. 305 - 320.

DANTAS, Eustogio; LUSTOSA, Ma Clelia. Vulnerabilidade socioambiental na regiâo metropolitana de 
Fortaleza. Fortaleza, Universidades Federao de Ceará-CNPQ - Observataorio das Metropolis. 2009, 298 p. DODSON, Jago; NEIL, Sipe. Oil Vulnerability in the Australian City: Assessing Socioeconomic Risks from Higher Urban Fuel Prices. Urban Studies., vol. 44, $\mathrm{n}^{\circ}$ 1, enero 2007. p. 37-62.

FORMAN, Marianne; JORGENSEN, Michael, S. Corporate environmental competence: The effects of networking, organizational learning and preventive strategies. Management of Environment in a Network Perspective. Copenhague, Technical University of Denmark, 2, spring 2005, 21 pp.

FUNTOWICZ, Silvio. Problemas ambientales complejos y la ciencia postnormal. Sostenible. Congrés Internacional Tecnologia, Desenvolupament Sostenible i Desequilibris. Barcelona, Icaria - Generalitat de Catalunya, 1997. pp. 189-205.

GARCIA, Ernest. Sociedad y Medio Ambiente. La civilización industrial y los límites del planeta. Madrid. Alianza Editorial, 2004, 356 pp.

GARCIA, H. Raquel; GONDIM, M.Fátima; SILVA, Marcia Regina. Políticas públicas e agricultura familiar: construindo caminos para o acceso aos mercados. VII Congresso Brasileiro da Agroecologia, Fortaleza, 2011. http://www.aba-agroecologia.org.br/ojs2/index.php/cad/issue/view/58

GEE, David; STIRLING, Andrew. Late Lessons from Early Warnings: Improving Science and Gobernance under Uncertainty and Ignorance. En: TICKNER, J.A. (Ed.). Precaution, environmental science, and preventive public policy. Washington, Island Press, 2003, 195-213.

GERRARD, S.; SIMPSON, A. La construcción social de la gestión de los residuos: conflicto y consenso. Residuos, Población y Medio ambiente. Serie Geográfica. Madrid, 1995, 5, 53-68.

GIL, Daniel; VILCHES, Amparo. L'atenció a la situació d'emergència planetària en l'educació científica. Revista del Col.legi de Doctors i Llicenciats de Catalunya. Barcelona, 2004, n 122.

GILLETTE, E.A. The children of Yaqui Valley: Precautionary Science and Community. En: TICKNER, J.A.(Ed.). Precaution, environmental science, and preventive public policy. Washington, Island Press, 2003. 321-331.

GUERRA DANERI, Enrique. Aspectos jurídicos de la responsabilidad en agricultura transgénica. Rivista de Diritto Agrario. Milano: LXXIX, 2, abril - junio 2000. p. 207-227.

HEWITT, Nicola. Guia Europea per a la planificació de les Agendes 21 Locals. Barcelona: Ajuntament de Barcelona - ICLEI European Secretariat, 1996, 120 pp.

Integrated Pest Management Policy (IPM). Los Angeles Unified School District, 1998. http://www.calisafe. org/policy.html

JORDAN, William R. Sunflower Forest: Ecological Restauration as the Basis for a New Environmental Paradigm. En: BALDWIN, I; DE LUCE, Judith; DWIGHT, A.; PLETSCH, Carl. Beyond preservation: Restoring and inventing landscapes. University of Minnesota Press. Minneapolis, 1994, pp. 17 - 34.

JORGENSEN, M.S.: Polítiques d'habitatge sostenible a Dinamarca. En: ALIÓ, M À; JORI, G. (Eds.): Les sociertats urbanes davant la reforma ambiental. Visions i propostes al voltant de la sostenibilitat. Universitat de Barcelona - 2GES, 2011, 41-47

JORI, Gerard. El cambio climático como problema y el diálogo social como solución. Investigaciones Geográficas, Universidad de Alicante, 2009, $\mathrm{n}^{\circ}$ 48, p. 125-160.

KRIEBEL, David (et alter). The Precautionary Principle in Environmental Science. Environmental Health Perspectives, 109, n.9, agosto 2001. http://www.ncbi.nlm.nih.gov/pmc/articles/PMC1240435/

LE TRÉHONDAT, Patrik; SILBERSTEIN, Patrik. Katrina. El desastre anunciado. Madrid, El Viejo Topo, $158 \mathrm{p}$.

NAESS, Arne and ROTHENBERG, David (Ed.). Ecology, Community and Lifestyle : Outline of an Ecosophy. Cambridge University Press, 1989, 223 pp.

NAESS, A. The sallow and the deep, long-range ecology movement. A summary. Inquiry: an Interdisciplinary journal of Filosophy. Vol 16, 1-4, 1986.

O'RIORDAN, Timothy: JORDAN, Andrew. The Precautionary Principle in Contemporary Environmental Politics. Environmental Values. n.4, 1995, 191-212.

O'RIORDAN, Timothy; JORDAN, Andrew. The Precautionary Principle in Contemporany Environmental 
Policy and Politics. Wingspread Conference on Implementing the Precautionary Principle. Racine Wisconsin: 1998. http://www.johnsonfdn.org/conferences/precautionary/jord.html (9 de octubre de 2008) PEÑA, David. Vulnerabilitat urbana davant la hipòtesi de la crisi energètica a l'Àrea Metropolitana de Barcelona. Biblio 3w. Revista Bibliográfica de Geografía y Ciencias Sociales. Universitat de Barcelona, vol. $\mathrm{XV}, \mathrm{n}^{\circ} 887$ (4), 5 de septiembre de 2010. http://www.ub.edu/geocrit/b3w-887/b3w-887-4.htm

PORTA, Miquel et alter. Concentraciones de compuestos tóxicos persistentes en la población española: el rompecabezas sin piezas y la protección de la salud pública. Barcelona, Gaceta Sanitaria, 16, n.3, p. 257266, mayo-junio 2002.

PORTA, Miquel et alter. Concentraciones de compuestos tóxicos persistentes en la población española. Criterios para un diagnóstico de la situación actual. Gaceta Sanitaria, Barcelona: 20, n.3, mayo-junio 2006. p. 233-238.

QUEIROZ de ALMEIDA, Lutiane. Por uma ciencia dos riscos e vulnerabiliades na Geografia. Mercator - Revista da Geografia. Universidade Federal do Ceará, Fortaleza, 10, n.23, septiembre-diciembre 2011, p. 83-89.

RAFFENSPERGER, C. et alter. Principles of Perpetual Care. The Giant Mine, Yellowknife and Northwest Territories. Science and Environmental Health Network, The Networker, vol 17, n2. 2011. http://www. sehn.org/Volume_17-2.html

RIGOTTO, Raquel Maria (Ed). Agrotóxicos, trabalho e saúde: vulnerabilidade e resistência no contexto da modernização agrícola no Baixo Jaguaribe/CE. Fortaleza, Edições UFC, 2011, 612 p.

RIGOTTO, Raquel M. Agrotóxicos. Mapa de Conflitos Ambientais de Mina Gerais. GESTA-UFMG, Belo Horizonte / MG, 2011. http://conflitosambientaismg.lcc.ufmg.br/?pg=txtAnalitico

SANDBACH, Francis. Principles of Pollution Control. Longman Editions, London: 1982. 192 p.

SCOTTI, Antonio. Ciudades resilientes. En: ALIÓ, M. À.; JORI, G. Eds. Les sociertats urbanes davant la reforma ambiental. Visions i propostes al voltant de la sostenibilitat. Universitat de Barcelona - 2GES, 111-128.

TICKNER, Joel A.; Raffensperger, Carolyn; Myers, Nancy. The Precautionary Principle in Action. A Handbook. Science and Environmental Health Network, 2001, 23 p. http://www.mindfully.org/Precaution/ Precaution-In-Action-Handbook.htm

TICKNER, Joel A. (Ed.). Precaution, environmental science, and preventive public policy. Washington, Island Press, 2003. 406 p.

Transdisciplinarity: Joint Problem-Solving among Science. Technology and Society. International Transdisciplinarity 2000 Conference. Zurich, Swiss Federal Institute of Technology - UNESCO, febrero y marzo 2000, 2 vols.

TRUDEAU, Héléne; BEAULNE-BÉLISLE, Kateri; LEROUX, Thérèse. Retour vers le passé: Le principie de précaution et la régulation des substances toxiques au Canada. Revista Catalana de Dret Ambiental, Barcelona: vol I, 1, 2010. 1-53.

TURNER II, B.L.; MATSON, P. A.; KASPERSON, R. E.; KASPERSON, J. E. X. Vulnerability in Human-Environment Relationships. AAAS Symposium: Science and Technology for a Transition toward Sustainability. Boston. 2002. http://ksgnotes1.harvard.edu/bcsia/sust.nsf/pubs/pub57 (9 de octubre de 2008).

WHITE PAPER. The Precautinonary Principle and the City of San Francisco. Marzo 2003. 21 pp.

Trabalho enviado em novembro de 2012

Trabalho aceito em dezembro de 2012 